\title{
Mudanzas boleras, la escuela bolera en el arte del siglo XIX
}

Mudanzas boleras, the bolera school in 19th century art

Carmen Manuela Rocamora Jiménez

Conservatorio Superior de Danza de Málaga “Ángel Pericet” (rocamoracsdm@gmail.com)

Recibido el 26 de febrero de 2018; revisado el 11 de marzo de 2018; aceptado el 27 de mayo de 2018; publicado el 12 de julio de 2018

RESUMEN: La escuela bolera actualmente es un estilo englobado dentro de la danza española que surgió en el siglo XVIII cuando los bailes populares españoles comenzaron a profesionalizarse debido en parte a la influencia del ballet clásico que había llegado a nuestro país procedente de Italia en ese mismo siglo. Este estilo dancístico propiamente español tuvo su auge en el siglo XIX, momento en el que fueron muchos los artistas plásticos que dejaron testimonio de ello en grabados y pinturas, ya fueran retratos de los intérpretes más destacados o escenas de costumbres. Este trabajo tiene como finalidad recoger una serie de pinturas, grabados y esculturas del siglo XIX que reflejan la escuela bolera, la cual ha pasado siempre desapercibida a la sombra del flamenco, o incluso ha sido confundida con este estilo, muy en boga en los últimos tiempos.

PALABRAS CLAVE: Escuela bolera, Pintura costumbrista, Barros malagueños, Viajero romántico, Pintura costumbrista, Flamenco, Danza española.

\begin{abstract}
The escuela bolera is currently a style encompassed within the Spanish dance that emerged in the eighteenth century when Spanish popular dances began to professionalize due in part to the influence of classical ballet that had come to our country from Italy in that same century. This Spanish dance style had its culmination in the 19th century, when many plastic artists left their testimony in engravings and paintings, whether they were protraits of the most outstanding interpreters or scenes of customs. This work aims to collect a series of 19th century paintings, engravings and sculptures that reflect the escuela bolera, which has always gone unnoticed in the shadow of flamenco, ore ven has been confused with this style, much in vogue in the last time.
\end{abstract}

KEYWORDS: Escuela bolera, Barros malagueños, Romantic traveler, Genre painting, Flamenco, Spanish dance. 


\section{Aproximación al concepto}

La escuela bolera es una rama o estilo de la Danza Española junto con el folklore, el flamenco y la danza estilizada, originada en el siglo XVIII, época en la que se empezaron a codificar los bailes populares de la Península Ibérica. Estos bailes se comienzan a academizar y reelaborar con una gran influencia de la técnica del ballet que había irrumpido en España en este mismo siglo procedente de Italia. El calificativo de "bolera" procede del apodo "boleros", empleado a partir del siglo XIX, con el que se conocía a los bailarines de este estilo de danza. Actualmente, la escuela bolera forma parte del currículum de enseñanza de los conservatorios profesionales de toda España, gracias a lo cual se sigue conservando y transmitiendo todo el repertorio de pasos y bailes.

La escuela bolera se ejecuta en la actualidad con zapatillas de media punta o con chapines. El movimiento de la danza se acompaña con toque de castañuelas. Tiene como base la técnica de la danza clásica en cuanto a colocación, técnica de giro y técnica de salto. A esta técnica clásica se le añade el carácter español en el movimiento de torso, brazos y cabeza. Se emplea lo que se conoce como "braceo español", que al contrario que el port de bras de la danza clásica, utiliza movimientos más enérgicos y trabaja los contratiempos. Por su parte, la utilización del torso se caracteriza por los constantes quiebros o escorzos (Ruiz, 1999: p. 326). La indumentaria empleada en este tipo de danza recuerda al traje femenino propio de la zona de Madrid y Andalucía a finales del siglo XVIII y principios del XIX: un traje de fantasía con una falda algo más larga que un tutú romántico y adornada con todo tipo de encajes y abalorios.

En el siglo XIX se produce el apogeo de la escuela bolera, que se convierte en el género más aclamado y demandado en los teatros tanto dentro como fuera de nuestro país. La escuela bolera llegará principalmente a los teatros de Inglaterra, Francia y Dinamarca de la mano de bailarines nacionales y, también, de bailarinas clásicas que incluyen en sus repertorios piezas de carácter español. 


\section{Distinción entre la escuela bolera y el flamenco}

A lo largo de esta investigación nos hemos dado cuenta de la fina línea que para el público no entendido del siglo XIX separaba la escuela bolera del flamenco, y por tanto a sus intérpretes, los cuales solían bailar indistintamente un estilo u otro. Por este motivo en muchas pinturas se aprecia cómo el título habla de un baile o tipo de danza diferente al que se está realizando, confundiendo en ocasiones a boleras con flamencas.

El flamenco surge en el siglo XIX y presenta notables diferencias con la escuela bolera. Una de ellas es que el flamenco desecha el uso de las castañuelas como elemento acompañante del baile, pues los intérpretes del flamenco se acompañan de chasquidos de dedos. Musicalmente también encontramos rasgos diferenciadores, ya que los boleros podían acompañarse con numerosos tipos de instrumentos: bandurria, guitarra o violín, pero siempre sin voz, pues son piezas únicamente instrumentales, mientras que el flamenco solo se sirve de la voz humana y la guitarra, a las que suelen unirse jaleadores con oles y palmas que rodean y animan al intérprete (Cavia, 2013: p. 42). Por otra parte, el vestuario también se diferenciaba, sobre todo por la largura de las faldas: las de flamenco eran largas hasta los pies y las boleras mucho más cortas, a la altura de la rodilla, pues una mayor largura impediría la correcta realización de los pasos e impediría lucir los saltos y las rápidas combinaciones de pies (Cavia, 2013: p. 45).

\section{La literatura de viajes: el viajero romántico en España}

Las muestras de estampas y pinturas en las cuales aparece reflejada la escuela bolera se han extraído tanto de la literatura de viajes como de la pintura costumbrista. La literatura de viajes es considerada un género literario caracterizado por recoger las vivencias y descripciones, ya sean reales o imaginarias, de un viajero, con el objetivo de acercar todo ese conocimiento a todo aquel que pudiera estar interesado (Santos y Encinas, 2009: p. 5).

A finales del siglo XVIII y, durante el siglo XIX, España estaba experimentando su desarrollo considerablemente más lento que el resto de los países europeos, por lo que se convirtió en un foco de interés para aquellos viajeros románticos que buscaban lo exótico o diferente. Es así como a comienzos del siglo XIX, coincidiendo con la crisis de la razón ilustrada, nace un nuevo tipo de 
viajero, el viajero romántico, movido por la sensibilidad y el deseo de evasión que rompe con el dominio de la objetividad (González, 1987: p. 15).

Los libros de descripciones que realizaban los viajeros románticos europeos se conocen también por el nombre de "viajes pintorescos", ya que en ellos se recogían descripciones sobre tipos populares, bailes, fiestas, etc., en definitiva, todo lo que les resultaba pintoresco (Méndez, 2008: p. $33)$.

El viajero romántico solía ir acompañado por un dibujante que sería el encargado de ilustrar los escritos. Uno de los viajeros que visita España en el siglo XIX fue Jean-Charles Davillier (Barón Davillier), coleccionista, doctor en artes y un gran hispanista, que visitó nuestro país entre diez y veinte veces. En 1862 realizó un viaje junto a Gustave Doré en el que fue escribiendo y publicando diversos escritos ilustrados por este último. Puesto que Doré era también músico, va a plasmar con especial veracidad las escenas donde interviene la música, las cuales serán realmente abundantes en esta obra1.

\section{La pintura costumbrista}

En cuanto a la pintura costumbrista, fue un género pictórico que surge en el siglo XIX teniendo como base los principios románticos, pero dejando a un lado el factor crítico de este movimiento al embellecer la realidad sin mostrar los aspectos más crudos de la misma. El fin del costumbrismo era ensalzar los aspectos más amables y pintorescos de la sociedad, enmascarando los menos gratos de la realidad. En este empeño, esta corriente va a reproducir no hechos inventados, sino hechos reales seleccionados, motivo por el cual son numerosas las obras que muestran bailes, romerías, ferias, procesiones, corridas de toros, etc. Una de las principales características del costumbrismo, además de las ya citadas, es que, por lo general, presenta tipos, no personas concretas, es decir, toreros, bailarinas, mesoneros, etc. (Quesada, 1992: pp. 101-102).

Uno de los primeros tipos en aparecer fueron los majos y majas. Los majos fueron unos personajes surgidos en el siglo XVIII en las escalas más inferiores del pueblo madrileño que se caracterizaban por su gracia y donaire, así como por llevar un vestuario extraordinariamente adornado. Esta figura se extendió hasta llegar a Andalucía y comenzó a convertirse en protagonista de obras literarias y plásticas. La maja sería su equivalente femenino y se caracterizaría por su gracia

\footnotetext{
1 De los 309 dibujos que realiza para Viaje por España, 39 de ellos guardan relación con la música y la danza.
} 
y belleza. Una variación del tipo de maja es la bailarina, la cual se mantendrá en el centro de la composición agolpando a su alrededor al resto de personajes (Reina, 1979: p. 61). Esta bailarina va vestida con el traje tradicional bolero, consistente en una falda abullonada que cae hasta la altura de las rodillas, la cual suele estar adornada con encajes que simulan volantes. El corpiño del traje es ceñido y con un escote hasta los hombros, dejándolos al descubierto, ya sea de manga larga o corta. El corpiño, y en ocasiones el final de la falda, suele ir adornado con madroños. Por su parte, el pelo se mantiene siempre recogido y adornado con flores o cintas. En los pies calzan zapatillas de media punta, calzado empleado solo y exclusivamente para el baile.

Otra de las figuras más frecuentes del costumbrismo español es la del torero, éste suele representarse junto a una maja para incidir en la fama que estos hombres tenían entre las mujeres (Quesada, 1992: pp. 127-130).

En cuanto a las escenas, las que más nos incumben y que repercuten en el tema que nos ocupa, son los bailes que se realizaban, bien al aire libre en las romerías, o en fiestas improvisadas generalmente en mesones o en patios, donde encontramos bailes e intérpretes tanto de escuela bolera como de flamenco, acompañados de guitarristas, majas, toreros y demás asistentes que forman escenas secundarias participando en juegos de naipes o conversaciones. Cuando estos bailes suceden en el interior de tabernas nunca se muestra la total realidad de las mismas, sino que se centran en los intérpretes, músicos y asistentes al baile, mostrando, por tanto, un entorno parcial y escogido.

Los festejos más destacados en la pintura costumbrista fueron la feria de Mairena (Sevilla), como lugar de compra y venta de ganado, cuyos propietarios asistían con sus mejores trajes; la romería del Rocío, la feria de Sevilla, otra feria mercantil, hecho que omiten los pintores, poniendo su foco en retratar el contraste de los diversos tipos de gente que allí se agolpaban, desde buñoleras, hasta caballistas, campesinos o gitanos, y la feria de Santiponce, otra feria de ganado de esta pequeña localidad sevillana donde se mantenían más arraigadas las costumbres tradicionales ajenas a toda influencia extranjera (Reina, 1979: pp. 83-86). 


\section{La escuela bolera en imágenes}

A lo largo del siglo XIX van a ser numerosas las pinturas y estampas que van a reflejar la escuela bolera, tanto por parte de pintores nacionales como por extranjeros, lo que va a suponer una fuente imprescindible para el estudio de este estilo, aunque debemos tener en cuenta que dichas representaciones van a ser, en mayor o menor medida, ficticias, pues como ya se ha tratado más arriba, la objetividad no era el fin del costumbrismo. La representación prototípica de la bailarina de escuela bolera en el XIX la proporciona Antonio Cabral Bejarano en Una bolera (1842) [1]. Se trata de un retrato de una joven sobre un paisaje en el que podemos ver el río Guadalquivir a su paso por Sevilla y, sobre él, la Torre del Oro, por lo cual la protagonista se sitúa en el barrio de Triana.

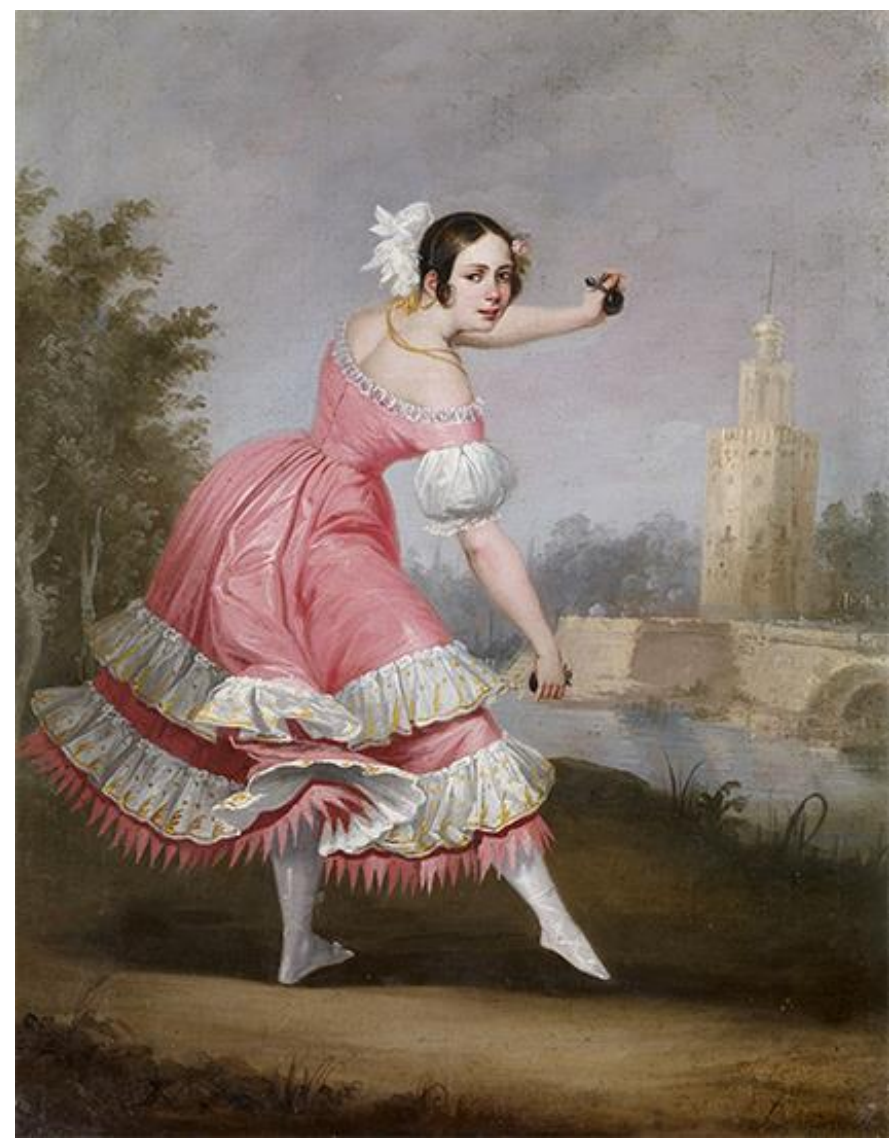

1. Una bolera (1842), Antonio Cabral Bejarano. Museo Carmen Thyssen Málaga.

Procedencia: Museo Carmen Thyssen Málaga (MCTM): http://carmenthyssenmalaga.org/obra/una-bolera

La bailarina, anónima, está ejecutando un baile de escuela bolera que posiblemente sea el "Olé de la Curra" debido a la posición característica de éste: se encuentra con la pierna base ligeramente flexionada y la otra estirada al lado, presentando el torso inclinado hacia dicha pierna y 
la cabeza girada hacia ese perfil. Los brazos terminan de dar dinamismo al retrato, pues no se encuentran en una posición fija, sino en el tránsito entre una de las posiciones fijadas y otra.

En cuanto a la indumentaria y complementos, además de las castañuelas, adornos en el pelo y joyas, viste un vestido con el típico escote hasta los hombros. La falda lleva dos volantes blancos con adornos dorados. Por último, calza zapatillas de media punta blancas.

Esta obra cuenta al menos con dos copias idénticas más, donde apenas cambia algún detalle vegetal del paisaje. De estas dos copias, la del palacio de las Dueñas de Sevilla conserva su pareja masculina, Majo bailando (ca. 1840-1845). El majo está retratado, al igual que la maja, bailando bolero, con una pose totalmente complementaria a la de su pareja, aunque con una actitud dancística muy pobre: piernas y pies hacia dentro y brazos "caídos". La pose está en una supuesta simetría con la obra que le hace pareja, la cual se colocaría a la izquierda de la que nos ocupa, de manera que las figuras forman una verdadera pareja de baile en obras separadas.

El fondo del paisaje muestra la catedral de Sevilla y la Giralda, y se desarrolla también en la orilla del Guadalquivir perteneciente al barrio de Triana (Valdivieso, 2014: p. 109). Otra de las obras a destacar de Antonio Cabral Bejarano es Amparo Álvarez «La Campanera», una de las bailarinas y maestras más populares de Sevilla [2]. Es un retrato de tamaño natural. Se la representa en actitud orientada a la diagonal y con el torso y cabeza vueltos de frente al espectador. Sostiene en una mano un abanico abierto, a la altura del pecho y luce un vestido de bolera rojo con adornos de encaje dorado que simulan volantes en la falda y marcan los puños de las mangas y la separación de la falda con el corpiño. El abanico, además de ser un elemento decorativo en el retrato, es uno de los elementos con el que se pueden ejecutar ciertos bailes del repertorio bolero, como en el caso de "La maja y el torero".

De este pintor también es el retrato de Josefa Vargas (ca. 1850), sumándose al catálogo de artistas que plasman en sus obras a esta afamada bailarina bolera. Esta obra pertenecía al periodo en que Josefa Vargas triunfaba en Sevilla, poco antes de marchar a recorrer el resto de España y Europa (Valdivieso, 2014: p. 148). Se trata de un retrato a tamaño natural, que hace pareja con el de $L a$ campanera, anteriormente descrito. En él la bailarina aparece prácticamente de frente al espectador en actitud, es decir, con la pierna de base estirada y la otra extendida hacia delante con el pie estirado y girado hacia fuera. Mantiene un brazo erguido hacia arriba sujetando una pandereta con cintas y el 
otro brazo lo apoya en la cintura. La pandereta no se considera un elemento para acompañar el baile de la escuela bolera, por lo que su aparición en el retrato es puramente decorativa.

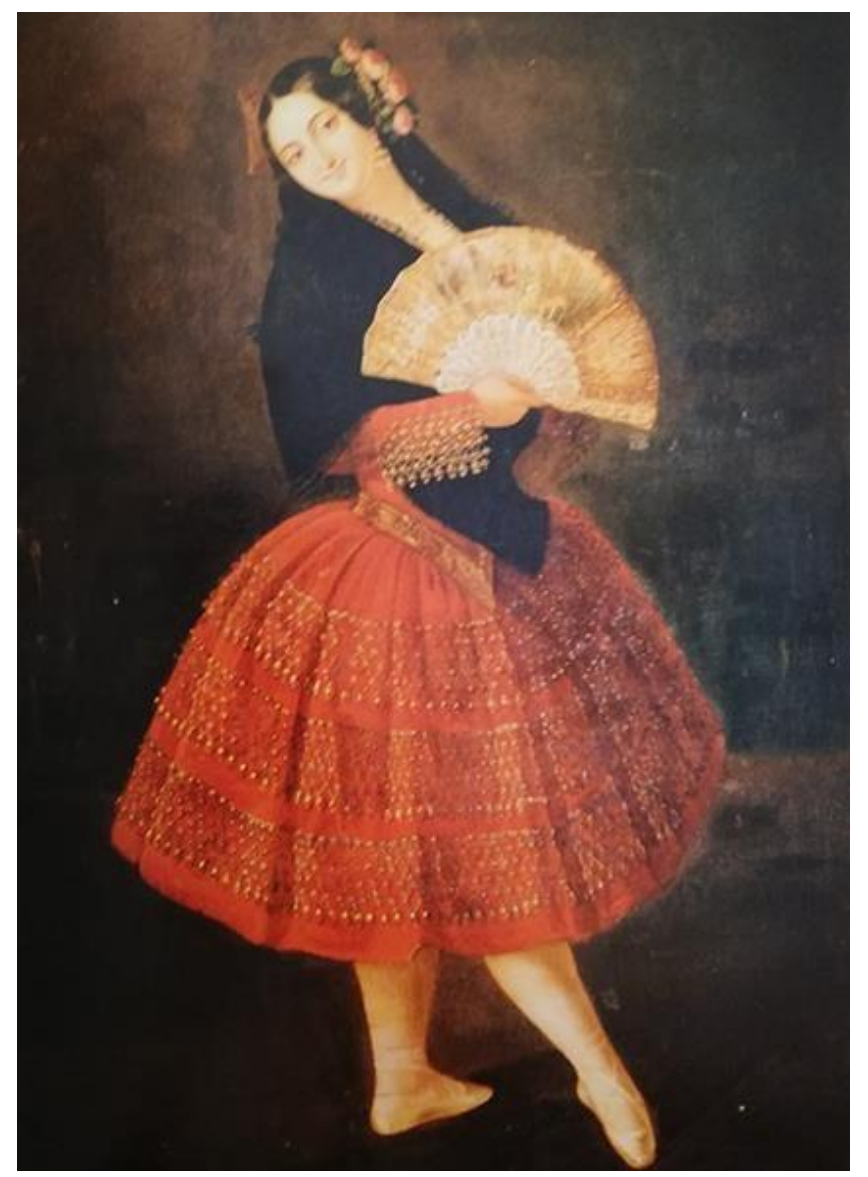

2. Amparo Álvarez "La Campanera" (1850), Antonio Cabral Bejarano. Colección particular, Sevilla.

Procedencia: (Valdivieso, 2014: 151).

La bailarina aparece ataviada con un rico traje de bolera de color rosa con adornos blancos, medias blancas y zapatillas de media punta rosas. Destaca el adorno floral que presenta el corpiño a la altura del vientre. Mención aparte merecen aquellas obras donde el baile está encuadrado en contextos cotidianos, tanto en el interior como en el exterior de mesones y ventas o en ferias y romerías. Uno de estos ejemplos es Baile en un mesón (ca. 1841), de Joaquín Domínguez Bécquer [3]. Se representa una escena de baile en lo que parece ser el interior de un mesón. Los bailarines son dos parejas de boleros ejecutando un baile en cuadrado, alternando figuras masculinas y femeninas. Este baile puede ser las seguidillas boleras, pues parece que están realizando uno de los pasos que forman parte del estribillo, el cual se repite antes de cada copla. Las seguidillas boleras es un baile muy saltado o botado, y parece que los bailarines de esta pintura pudieran estar realizando uno de los 
saltos de dicho baile. Destaca el carácter de la danza española con los brazos recortados fruto del característico braceo español, así como la posición inclinada del torso.

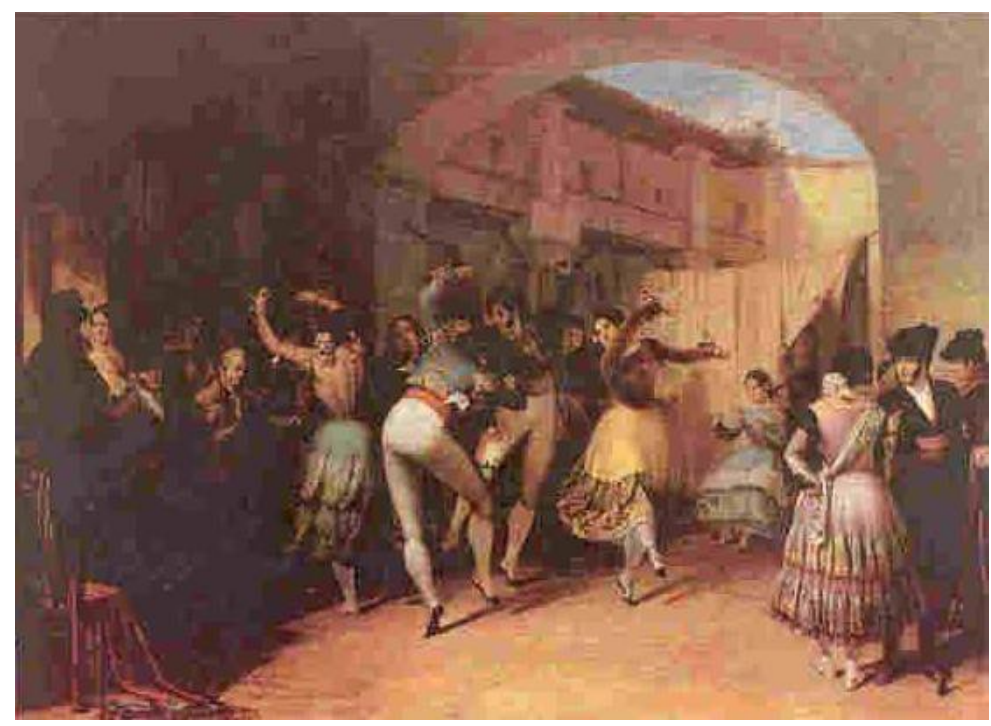

3. Baile en un mesón (1841), Joaquín Domínguez Bécquer.

Procedencia: Enciclopedia de Danza, "Breve historia del flamenco. Bailes pre-flamencos". En: http://www.elitearteydanza.com.ar/enciclopedia-breve-historia-flamenco-bailes-preflamencos.htm

Otro ejemplo nos lo proporciona Francisco de Paula Escribano con Un baile en Triana (1850). Sobre un paisaje de la ciudad donde se ve el río Guadalquivir y al otro lado monumentos representativos de Sevilla como la Torre del Oro o la Giralda, se nos presenta un grupo de personas a la puerta de lo que podría ser una venta o una taberna. Algunas están comiendo, otras tocan instrumentos e incluso podemos ver varios personajes a caballo al fondo. La escena central la protagoniza una pareja que se encuentra ejecutando un baile, el cual por la posición que presenta, podemos deducir que es propio de la escuela bolera. Ambos tienen exactamente la misma postura: la pierna base semiflexionada y la otra extendida a un lado, hacia el cual se inclinan, con el brazo de dicho lado hacia abajo y el otro arriba en quinta posición. Es una postura muy repetida en los bailes de repertorio de la escuela bolera, pero sobre todo es propia del "Olé de la Cura". En este caso, los bailarines no van vestidos como los típicos boleros, pero sí llevan castañuelas y ella calza zapatillas de media punta.

También se han querido incluir en la presente investigación los grabados realizados por Gustave Doré en 1862 para ilustrar los textos del Barón Davillier, en Viaje por España. Uno de estos ejemplos es Los panaderos, uno de los bailes del repertorio de la escuela bolera, representado por una pareja de boleros que se dan la espalda mientras ejecutan un paso que podría interpretarse como 
"el paso de panaderos", aunque más bien los personajes parecen estar posando y no ejecutando un paso, debido a la posición estática de pies en cuarta posición. Por otra parte, la posición de brazos y cabeza tampoco coincide con el paso de panaderos, lo cual indica que Doré no está captando la esencia del baile, sino que casi retrata al a pareja de boleros como tipos, bajo el título del baile de panaderos.

Otro de los bailes que muestra Doré es el de La malagueña y el torero, siendo en este caso un testimonio mucho más fiel en lo que respecta al baile, representando un fragmento en el cual casi a modo de pantomima danzada, la bolera coquetea con el bolero, que interpreta el papel de torero, haciéndole desplante u ocultándose tras el abanico; mientras que el torero acude una y otra vez en su búsqueda, sosteniendo el capote y la montera [4].

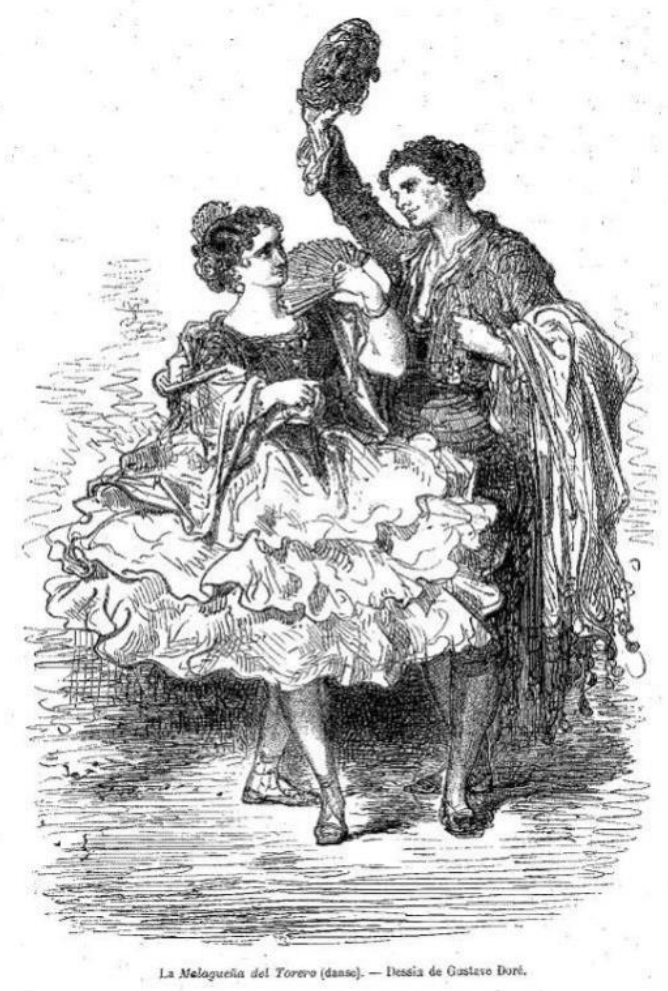

4. La malagueña y el torero (1862), Gustave Doré.

Procedencia: OLIVARES, Gabriel M., (2016). "La danza española vista por Gustavo Doré (II). En: https://www.albidanza.com/single-post/2016/12/18/LA-DANZA-ESPA\%C3\%910LA-VISTA-POR-GUSTAVODOR\%C3\%89-II

Por último, la investigación se centra en el caso excepcional de los barros malagueños. En Málaga, desde finales del siglo XVIII, hay escultores dedicados a la fabricación de pequeñas esculturas o figuras de barro, las cuales comenzaron siendo religiosas por influencia de la tradición de los belenes o presepi napolitanos, que alcanzaron fama en nuestro país con la subida al trono de 
Carlos III. Poco a poco la realización de figuras de temática popular fue ganando terrero en la producción de dichos artistas debido sobre todo al interés que estas esculturas despertaban en el amplio número de viajeros extranjeros que llegaban hasta Málaga (Romero Torres, 2006: pp. 8-9).

Estos viajeros quedaban prendados por la precisión y colorido de un sinfín de figuras que representaban a tipos populares, y que iban desde esculturas de meros campesinos, hasta toreros, bandoleros, e incluso danzantes. Se baraja la hipótesis de que la producción seria de estas figuras se combinara con encargos mediante la copia del natural, retratando a algún importante personaje, evidentemente con un coste más alto. Estas figurillas seguirán, en mayor o menor medida, la representación de tipos españoles creada por Gustave Doré en las ilustraciones de Voyage en Espagne (Pedraza, 2011: p. 171).

Centrándonos en las obras, José Cubero cuenta con una pareja de boleras que presentan una pose totalmente complementaria [5]. Ésta consiste en una cuarta posición de piernas que permanecen rotadas hacia fuera, con el talón de la pierna de delante levemente levantado. Ambas figuras ofrecen el perfil de la pierna adelantada. Los brazos están en cuarta posición, es decir, el brazo exterior en quinta y el interior en primera posición, con el que sujetan la falda. El torso, por su parte, se encuentra rotado e inclinado hacia atrás, acompañándose de la cabeza que se mantiene igualmente inclinada. Sorprende la calidad con la que está tratada la anatomía de estas figuras, las cuales presentan la postura bolera prácticamente a la perfección.

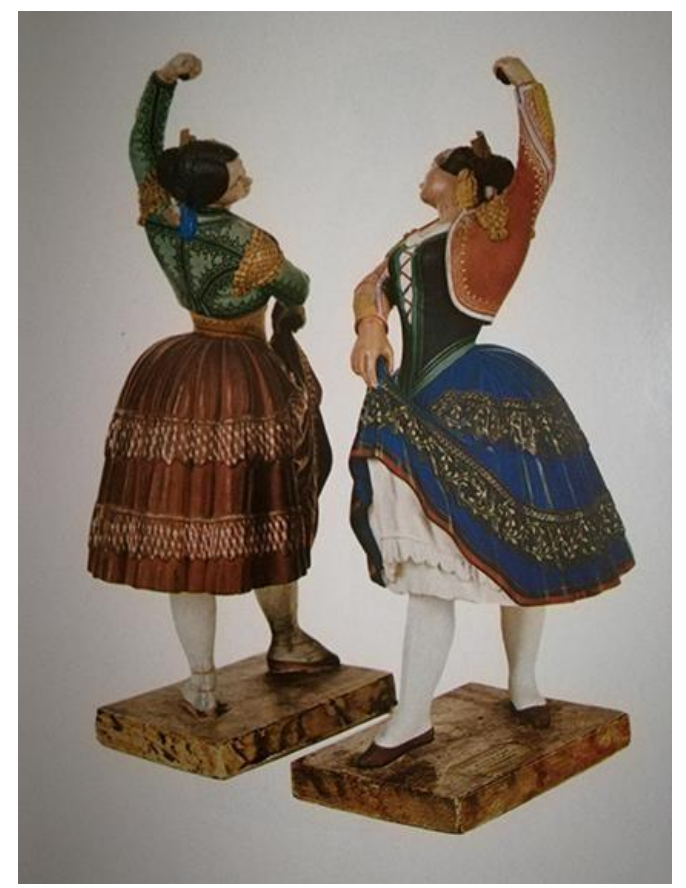

5. Pareja de boleras, José Cubero. Procedencia: (Peña, 1971: 59). 


\section{Conclusiones}

Las diferentes muestras de pintura, grabados y escultura son una excelente forma de acercarnos a la estética, formas y principales figuras de la escuela bolera del siglo XIX, así como a su interrelación con el pueblo de la época. Es importante y complejo, por la ausencia de estudios previos, el análisis de las diferentes obras que reflejan la escuela bolera, así como su diferenciación con otra serie de obras muy similares que reflejan el baile flamenco. Para realizar esta distinción nos hemos tenido que remitir únicamente a aspectos técnicos y estilísticos diferenciadores de ambos estilos dancísticos tales como indumentaria, acompañamiento musical, postura del ejecutante, etc.

El análisis de estas y otras muestras de la escuela bolera en el arte es útil de cara al mundo de la danza a la hora de transmitir el estilo de la misma, construir su historia ya que las fuentes escritas son escasas y, por último, estudiar la evolución de dicho estilo desde sus orígenes hasta la actualidad.

\section{Referencias bibliográficas}

CAVIA NAYA, Victoria (2013), "Mujeres, música, teatro y variedades: de las boleras y flamencas a las bailarinas de danza española (1885-1927), Cuadernos de música iberoamericana, vol. 2526, pp. 39-61.

GALÁN, Eva V. (1994), Pintores del Romanticismo andaluz, Universidad de Granada, Granada. GONZÁLEZ TROYANO, Alberto (1987), "Los viajeros románticos y la seducción "polimórfica” de Andalucía”, en GONZÁLEZ TROYANO, Alberto (y otros), La imagen de Andalucía en los Viajeros Románticos y Homenaje a Gerald Brenan, Diputación Provincial de Málaga, Málaga, pp. 11-21.

MÉNDEZ RODRÍGUEZ, Luis (2008), La imagen de Andalucía en el arte del siglo XIX, Centro de Estudios Andaluces, Sevilla.

PEDRAZA ALBA, Antonio (2011), "Los barros malagueños y el duque de Bedford", Péndulo: revista de ingeniería y humanidades, $\mathrm{n}^{\circ} 22$, pp. 158-173.

PEÑA HINOJOSA, Baltasar (1971), Barros malagueños, Obra Cultural de la Caja de Ahorros Provincial de Málaga, Málaga.

QUESADA, Luis (1992), La vida cotidiana en la pintura andaluza, Fundación Fondo de Cultura de Sevilla, Sevilla. 
REINA PALAZÓN, Antonio (1979), Pintura costumbrista en Sevilla (1830-1870), Universidad de Sevilla, Sevilla.

ROMERO TORRES, José Luis (2006), "Barros malagueños o Malaga Clay Figures”, en DE CASTEllo BRANCO, María, Barros Malagueños. Colección Durarte Pinto Coelho, Fundación Bancaja, Granada, pp. 8-24.

RUIZ MAYORDOMO, María José (1999), "Espectáculos de baile y danza: de la Edad Media al siglo XVIII" y "Espectáculos de baile y danza: siglo XIX”, en AMORÓS, Andrés y DÍEZ BORQUE, José María (coords.), Historia de los espectáculos en España, Editorial Castalia, Madrid, pp. 273-313 y 319-333.

SANTOS-ROVIRA, José María y ENCINAS ARQUERO, Pablo (2009), "Breve aproximación al concepto de la literatura de viajes como concepto literario", Revista Tonos Digital, n 17, pp. $1-9$.

SANZ, María Jesús (2000), "El barón Davillier viajero y coleccionista", Laboratorio de arte, $\mathrm{n}^{\circ}$ 13, pp. 223-240.

VALDIVIESO, Enrique (2014), Antonio Cabral Bejarano, Diputación de Sevilla, Sevilla.

VEGA, Jesusa (2004), "Viajar a España en la primera mitad del siglo XIX: Una aventura lejos de la civilización”. Revista de Dialectología y Tradiciones Populares, Vol. 59, n², pp. 93-125. 